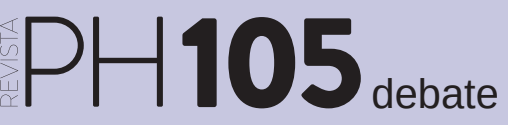

Interpretación y gestión del patrimonio en los espacios del turismo oscuro

coordinan Óscar Navajas Corral y Maribel Rodríguez Achútegui

\title{
La mercantilización de la memoria histórica y su denuncia en novelistas contemporáneos: análisis de El impostor de Javier Cercas
}

Alfonso Hidalgo Mañero | Graduado en Lengua y Literatura Españolas

URL de la contribución <www.iaph.es/revistaph/index.php/revistaph/article/view/5021>

\section{Introducción}

La memoria es "la facultad psíquica por medio de la cual se retiene y recuerda el pasado" (RAE s.f., definición 1). Mientras que la memoria individual está conformada por las vivencias y percepciones personales, la memoria colectiva son los recuerdos comunes de una colectividad (Luengo 2012, 14). Puesto que las colectividades no pueden ser entendidas como un grupo homogéneo, pueden coexistir diferentes formas de construir memoria que se pueden combinar o confrontar. Así pues, la memoria colectiva y la interpretación de los valores asociados a los espacios patrimoniales son un campo de disputa discursiva en el que participan diferentes actores con la intención de imponer sus intereses o creencias .

Estos conflictos discursivos son especialmente frecuentes en los sitios relacionados con la memoria histórica. Esta, entendida como un conjunto de recuerdos con connotaciones cívico-políticas de una colectividad, reinterpreta los hechos del pasado (Halbwachs 1995, 210). Además, en el contexto democrático español es uno de los derechos fundamentales de la ciudadanía (Luther 2010, 45). Desde esta perspectiva, profundizar en la forma en la que se construyen la memoria histórica y en cómo operan los mecanismos de reinterpretación del pasado en espacios patrimoniales ayuda a entender cómo la sociedad percibe los hechos históricos desde el presente (Colmeiro 2005, 8).

Algunos autores como Winter y Sivan (1999) han identificado a los actores de la esfera pública como un factor influyente en la construcción de la memoria colectiva. Los novelistas serían un ejemplo significativo de acto- res públicos. Por medio de sus textos, llegarían a la opinión pública (O'Donoghue 2019, 23) y la repercusión social de sus discursos les permitiría modelar la memoria colectiva (Luengo 2012, 27).

En esta línea, el concepto de posmemoria, definido por Marianne Hirsch (2008) es de gran utilidad para comprender los procesos asociados a la construcción de la memoria que se realizan desde el presente. La posmemoria es el conocimiento sobre un hecho traumático que presenta un individuo alejado espacial y temporalmente del evento histórico. Es decir, la memoria sobre los hechos traumáticos del pasado de aquellos individuos que no los han vivido.

Para el caso español, la construcción de la memoria sobre la Guerra Civil en el siglo XX debe entenderse en un contexto de dictadura (1939-1975) que impuso una homogeneización del discurso sobre el pasado y la conformación de una nueva memoria considerada "oficial" (Luengo 2012, 72; Romera Castillo 2013, 180). Tras la muerte del dictador Francisco Franco en 1975, el olvido fue una parte indispensable en la construcción de la memoria. Para estabilizar el proceso de transición democrática, muchos acontecimientos históricos fueron omitidos y ciertos puntos de vista marginados (Yusta Rodrigo 2011, 4-6; Vilarós citado en Luengo 2012, 86-87; Florenchie 2014, 939).

A partir de la década de los 90, se empieza a trabajar con fluidez desde un cuestionamiento crítico la memoria franquista, se sucede un incremento de las publicaciones relacionadas con la Guerra Civil y la posguerra 
(Florenchie 2014, 938; Luengo 2012, 91-92) y empiezan los procesos de investigación y recuperación de sitios memoriales. Este auge puede relacionarse en el ámbito internacional con numerosas investigaciones sobre la memoria del Holocausto (Florenchie 2014, 939), con una "explosión pública y mediática de la memoria de los vencidos" (Yusta Rodrigo 2011, 5) y el surgimiento, por iniciativa popular, de una serie de movimientos asociativos que agrupaban diferentes colectivos de vencidos de la Guerra Civil (Yusta Rodrigo 2011, 6-8). Por tanto, el turismo oscuro comenzará en estas fechas.

En el contexto expuesto, estudiar el género literario histórico permite analizar cómo los autores-descendientes reformulan imaginativamente la memoria histórica (Ciancio 2015, 512; Liikanen 2006, 2-3), y conocer los procesos de construcción memorial y patrimonial. Desde este marco conceptual, este texto discute los procesos de construcción de la memoria histórica española del siglo XX a través del análisis de la obra de Cercas El impostor.

\section{El impostor de Cercas y la crítica a la construcción de la memoria histórica}

Javier Cercas es uno de los autores más representativos y mediáticos de la novela española contemporánea. En su obra muestra especial interés en tratar hechos históricos del pasado reciente y la investigación histórica. El éxito de algunas de sus obras y la relación que a menudo tienen con el pasado de España, como Soldados de Salamina (Cercas 2001), lo convierten en un agente-público relevante en la construcción de la memoria de la Guerra Civil.

Si bien el autor había mostrado un interés sobre la recuperación de la memoria, en sus obras más recientes como El impostor (Cercas 2014), muestra una visión crítica de los procesos de construcción de la memoria histórica. En esta novela se investiga desde la autoficción el enigmático caso de Enric Marco, un personaje público que falseó su biografía hasta reconstruirse en un superviviente del campo nazi de Flossenbürg, y cuyo testimonio llegó hasta el Congreso de los Diputados (Ródenas de Moya 2019, 46).
A continuación se exponen los resultados del análisis de la obra El impostor distinguiendo tres niveles textuales: historia, narración y relato. Los resultados obtenidos permiten diferenciar los cambios en el concepto de construcción de la memoria histórica que el autor muestra.

\section{Análisis literario y discusión de El impostor}

En el plano del análisis histórico, se identifican los acontecimientos históricos más relevantes expuestos en la novela. En concreto, se hacen referencia a la Guerra Civil , la dictadura franquista, la transición, el Holocausto y la II Guerra Mundial. La presentación de estos hechos muestra una tendencia a profundizar en aspectos del pasado nacional silenciados por el franquismo o durante la transición a través de la presencia de personajes históricos y asociaciones caracterizadas por su lucha antifranquista.

A nivel narrativo, se reflexiona sobre las características narrativas que utiliza Javier Cercas para transmitir el pasado. La alternancia de perspectivas narrativas (autodiegética y heterodiegética) permite al autor diferenciar los hechos del pasado con los que el narrador-personaje mantiene una relación de experiencia directa y aquellos con los que no. Estos conocimientos transmitidos, son procesos posmemoriales como la participación de Enric Marco en la Guerra Civil o el Holocausto. A través de la voz narrativa, el autor visibiliza la necesidad de contrastar la información no vivida, es decir aportada por los testigos.

El análisis del relato permite comprender los procesos memoriales de reconstrucción del pasado. El autor utiliza el conflicto entre los personajes para representar la memoria histórica como un espacio de intereses. La narración sobre el pasado presenta una duplicidad de relatos: el propio del personaje-narrador, y el defendido por Enric Marco, ambos presentan una disputa constante por la construcción del relato memorial.

Las problemáticas señaladas por Cercas plantean un modelo de análisis capaz de explicar las tensiones político sociales asociadas a la resignificación, uso y 


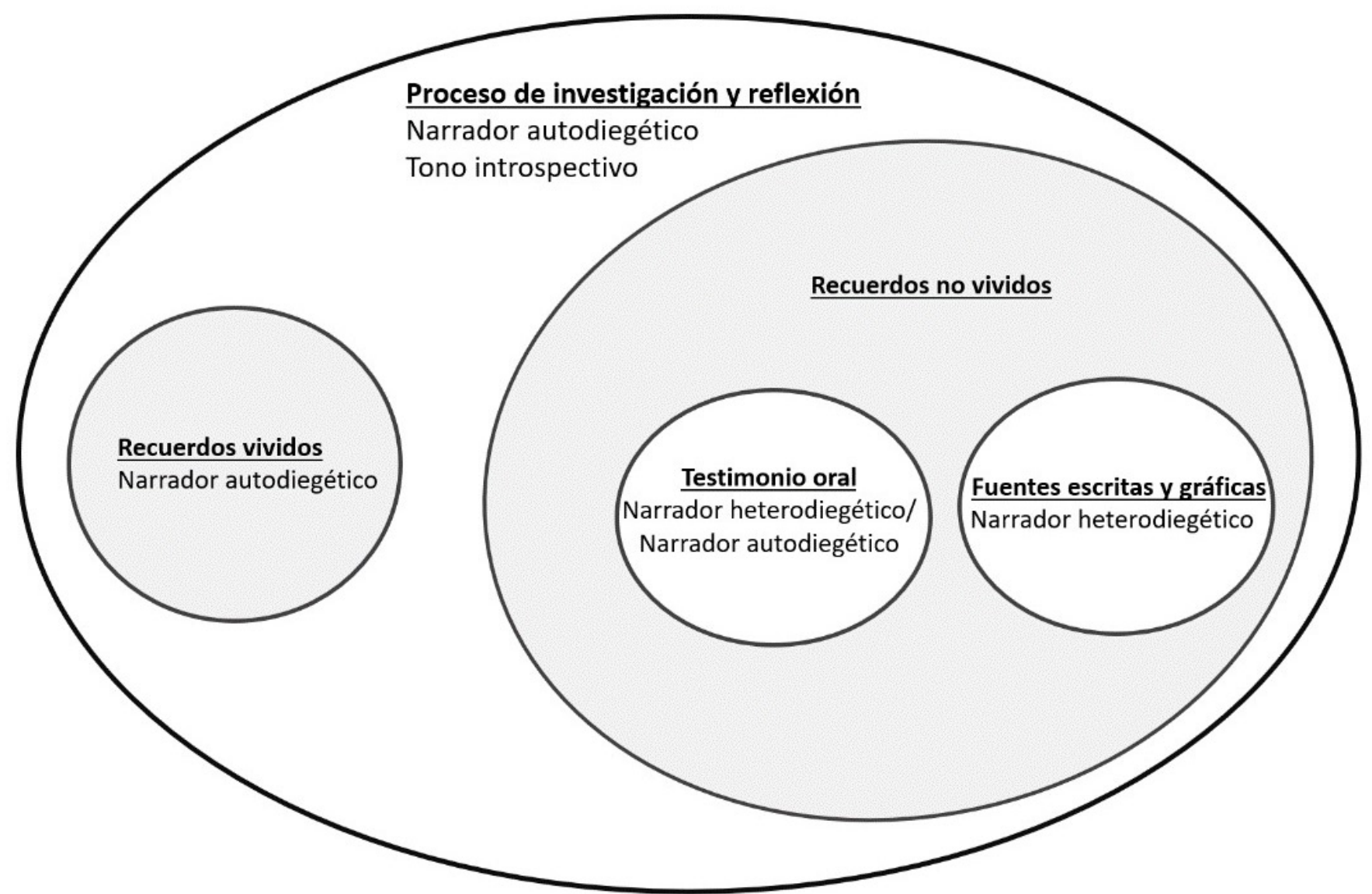

puesta en valor de espacios oscuros memoriales. Un ejemplo de actualidad sería el de las Torres de Meirás, hito memorial franquista, recientemente resignificado como símbolo del expolio de la dictadura. Las palabras de Carmen Calvo, por aquel entonces Vicepresidenta Primera del Gobierno, en relación con Las Torres de Meirás, dejan constancia de las tensiones generadas en torno a memoria, hechos históricos y democracia: "como sitio histórico, deben ser un lugar de memoria histórica democrática" (Rodríguez 2020).

\section{Conclusiones}

El caso de estudio presentado permite comprender y reflexionar sobre la construcción de la posmemoria histórica española del siglo XX desde la novela. De forma conjunta los datos expuestos permiten concluir que Cercas en su obra El impostor centra el foco de interés en las tensiones asociadas a la creación de discursos posmemoriales y a dos problemáticas derivadas del boom de la memoria histórica: la sacralización del testigo y los procesos de falsificación histórica.

Aplicados a la puesta en valor de espacios patrimoniales, los problemas expuestos en la novela explican los mecanismos discursivos que subyacen bajo las tensiones político-sociales que se observan en los llamados espacios de turismo oscuro, así como la necesidad de incluir a los diferentes actores sociales en las políticas de puesta en valor de sitios memoriales. 


\section{BIBLIOGRAFÍA}

- Cercas, J. (2001) Soldados de Salamina. Madrid: Cátedra

- Cercas, J. (2014) El impostor. Barcelona: Literatura Random House

- Ciancio, M.B. (2015) ¿Cómo (no) hacer cosas con imágenes? sobre el concepto de posmemoria. Constelaciones. Revista de Teoría Crítica, n. ${ }^{0} 7$, pp. 503-515. Disponible en: http://www. proyectos.cchs.csic.es/fdh/sites/default/files/2-2 Ciancio.pdf [Consulta: 08/11/2021]

- Colmeiro, J.F. (2005) Memoria histórica e identidad cultural: de la postguerra a la postmodernidad. Barcelona: Anthropos

- Florenchie, A. (2014) La memoria novelada: hibridación de géneros y metaficción en la novela española sobre la guerra civil y el franquismo, 2000-2010-La memoria novelada II: ficcionalización, documentalismo y lugares de memoria en la narrativa memorialista española. Bulletin Hispanique, vol. 116, n. ${ }^{\circ}$ 2, pp. 938-942. Disponible en: https://journals.openedition. org/bulletinhispanique/3690\#authors [Consulta: 08/11/2021]

- Halbwachs, M. y Díaz, A.L. (1995) Memoria colectiva y memoria histórica. Revista española de investigaciones sociológicas, n. ${ }^{\circ} 69$, pp. 209-219. Disponible en: https:// dialnet.unirioja.es/servlet/articulo?codigo $=758929$ [Consulta: 08/11/2021]

- Hirsch, M. (2008) The generation of postmemory. Poetics Today, vol. 29, n. ${ }^{\circ} 1$, pp. 103-128. Disponible en: https://read. dukeupress.edu/poetics-today/article/29/1/103/20954/TheGeneration-of-Postmemory [Consulta: 08/11/2021]

- Liikanen, E. (2006) Novelar para recordar: la posmemoria de la Guerra Civil y el franquismo en la novela española de la democracia. Cuatro casos. Congreso Internacional la Guerra Civil Española 1936-1939. Sociedad Estatal de Conmemoraciones Culturales. Disponible en: https://dialnet. unirioja.es/servlet/articulo?codigo $=2574433$ [Consulta: 08/11/2021]

- Luengo, A. (2012) La encrucijada de la memoria: la memoria colectiva de la Guerra Civil Española en la novela contemporánea. Berlín: Tranvía / Verlag Walter Frey

- Luther, J. (2010) El derecho a la memoria como derecho cultural del hombre en democracia. Revista Española de Derecho Constitucional, pp. 45-76

- O'Donoghue, S. (2019) La herencia de la memoria y sus representaciones. Posmemoria y trauma: algunos problemas teóricos y sus consecuencias para la crítica literaria. Pasajes, n. ${ }^{\circ}$ 56, pp. 8-25. Disponible en: https://mobiroderic.uv.es/bitstream/ handle/10550/71864/6921517.pdf? [Consulta: 08/11/2021]

- Real Academia Española Diccionario de la lengua española, 23. ${ }^{a}$ ed., [versión 23.4 en línea]. Disponible en: https://dle.rae. es/ [Consulta: 24/10/2021]

- Ródenas De Moya, D. (2019) Prólogo. En: Cercas,J. Soldados de Salamina. pp. 13-188. Madrid: Cátedra

- Romera Castillo, J. (2013) Teatro español siglos XVIII-XXI. Madrid: UNED

- Vilarós, T. (1998) El mono del desencanto: Una crítica cultural de la transición española, 1973-1993. Madrid: Siglo $\mathrm{XXI}$

- Winter, J. y Sivan, E. (1999) War and Remembrance in the Twentieth Century. Nueva York: Cambridge University Press

- Yusta Rodrigo, M. (2011) ¿«Memoria versus justicia»? La «recuperación de la memoria histórica» en la España actual. Amnis. Revue d'Études des Sociétés et Cultures Contemporaines Europe/Amérique, n. ${ }^{\circ}$ 2. Disponible en: http:// journals.openedition.org/amnis/1482 [Consulta: 08/11/2021] 